\title{
Aberrant Activation of Heat Shock Protein 60/65 Reactive T Cells in Patients with Behcet's Disease
}

\author{
Jun Shimizu, ${ }^{1}$ Tomoko Izumi, ${ }^{1,2}$ and Noboru Suzuki ${ }^{1}$ \\ ${ }^{1}$ Department of Immunology and Medicine, St. Marianna University School of Medicine, 2-16-1, Sugao, Miyamae-ku, \\ Kawasaki 216-8511, Japan \\ ${ }^{2}$ Department of Medicine, Self-Defense Forces Central Hospital, Tokyo 154-8532, Japan
}

Correspondence should be addressed to Noboru Suzuki,n3suzuki@marianna-u.ac.jp

Received 16 July 2012; Accepted 23 August 2012

Academic Editor: Kamal D. Moudgil

Copyright () 2012 Jun Shimizu et al. This is an open access article distributed under the Creative Commons Attribution License, which permits unrestricted use, distribution, and reproduction in any medium, provided the original work is properly cited.

Behcet's disease (BD) is a multisystemic inflammatory disease and is characterized by recurrent attacks on eyes, brain, skin, and gut. There is evidence that skewed T-cell responses contributed to its pathophysiology in patients with BD. We found that heat shock proteins (HSPs) reactive T cells were prevalent in patients with BD. Here, we summarize current findings on HSP reactive T cells and their contribution to the pathogenesis in patients with BD.

\section{Introduction}

Behcet's disease (BD) is a systemic inflammatory disease, characterized by recurrent signs and symptoms of oral aphthosis, genital ulcers, skin lesions, and uveitis. It is well known that BD is prevalent along the Silk Route, but BD patients are occasionally found in other regions of the world.

The etiology of BD is largely unknown and skewed T-cell responses are associated with development and maintenance of BD [1]. Excessive cytokine productions by $\mathrm{T}$ helper type 1 (Th1) cells were reported using immunohistochemistry [2, $3]$ and intracellular cytokine staining $[4,5]$. Th1 dominance was observed in BD uveitis [6] and stomatitis as well [7]. We reported excessive Th1 cell infiltration in $\mathrm{BD}$ skin and intestinal lesions [8-10].

Immune responses against microbes and microbial antigens were thought to play an important role in the pathogenesis of BD. Regional differences of the disease distribution [11] suggested association of disease development with locally prevalent microbes. Oral health was often impaired in patients with $\mathrm{BD}$ and was correlated well with BD disease severity [12]. Streptococcus sanguinis is a commensal oral bacterium and often forms dental plaque. S. sanguinis was found frequently in oral flora in patients with BD and the strain showed uncommon serotype (KTH1) compared with the standard ATCC strains [13]. T cells and peripheral blood mononuclear cells (PBMCs) from patients with $\mathrm{BD}$ responded to $\mathrm{KTH} 1$ antigens and produced interferon $\gamma($ IFN $\gamma)$ and interleukin (IL)-12 [14]. Skin tests of streptococcal antigens caused various systemic reactions, such as fever, ocular attack, and genital and oral ulcer in patients with BD [15]. Accumulation of indirect evidence suggested participation of bacteria (or associated antigens) in the pathogenesis of $\mathrm{BD}$.

Pathergy reaction is a cutaneous phenomenon where a minor injury, such as a needle prick, causes major skin lesions, such as ulcerations, panniculitis, and pyoderma, and positive pathergy reaction is included in the diagnostic criteria for BD proposed by the International Study Group [16]. Massive neutrophil infiltration and subsequent T-cell infiltration were frequently observed pathologically in the lesion caused by the reaction, even without any exogenous microbes [2]. The underlying mechanisms of the reaction remain largely unknown. On the other hand, it was suggested that skin florae and some skin self-antigens played a role because bacterial sterilization of skin reduced the reaction [17].

Heat shock proteins (HSPs) function as an intracellular chaperonin for other proteins, and significant sequence homology is found between mammalian HSP and microbial HSP (Table 1). For example, mycobacterial and streptococcal HSP65 have more than 90\% homology, and mycobacterial HSP65 and human HSP60 have 42\% homology [18]. HSP60/65 were thought to be a major cause of the 
TABLE 1: Comparison of the amino acid sequences of human, Chinese hamster (C) HSP60, Escherichia coli (E), and Mycobacterium leprae (M) HSP65 [18].

\begin{tabular}{lrl}
\hline hHSP60 MLRLPTVFRQMRPVSRVLAPHLTRAYAKDVKFGADARALMLQGVDLLADAVAVTMGPKGRTVIIEQSWGS 70 \\
CHSP 60 \\
EHSP 65 \\
MHSP65
\end{tabular}

PKVTKDGVTVAKS IDLKDKYKNIGAKLVQDVANNTNEEAGDGTTTATVLARS IAKEGFEKISKGANPVEI 140

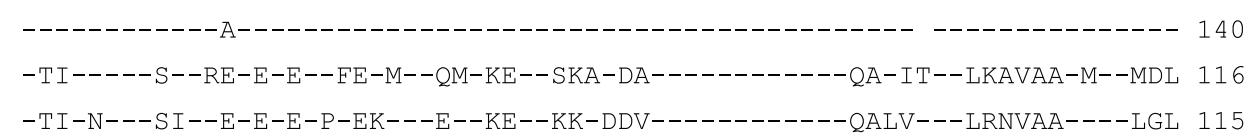

RRGVMLAVDAVIAELKKQSKPVTTPEEIAQVATISANGDKEIGNIISDAMKKVGRKGVITVKDGKTLNDE 210

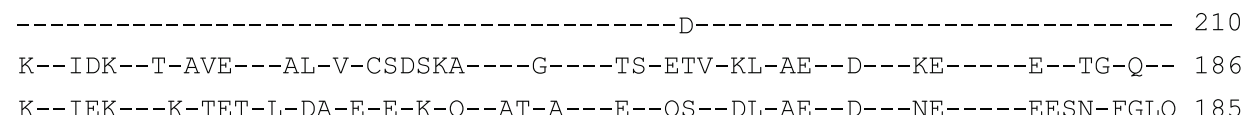

LEIIEGMKFDRGYISPYFINTSKGQKCEFQDAYVLLSEKKISSIQSIVPALEIANAHRKPLVIIAEDVDG 280

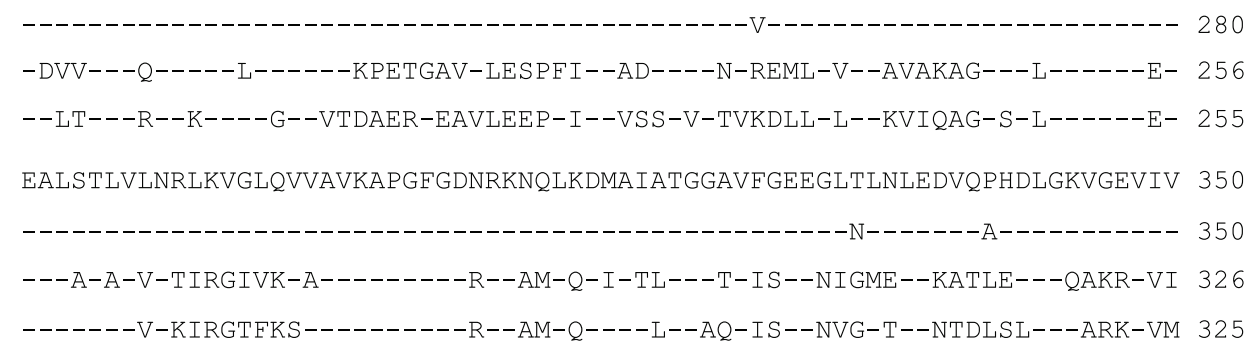

TKDDAMLLKGKGDKAQIEKRIQEIIEQLDVTTSEYEKEKLNERLAKLSDGVAVLKVGGTSDVEVNEKKDR 420

\begin{tabular}{|c|c|}
\hline N--TTTIID-V-EE-A-QG-VAQ-RQ-IEEA--D-DR---Q--V---AG----I---AATE--MK---A- & 396 \\
\hline ---ETTIVE-A--TDA-AG-VAQ-RTEIEMSD-D-DR---Q------AG----I-A-AATE--LK-R-H- & 395 \\
\hline VTDALNATRAAVEEGIVLGGGCALLRCIPALDSLTPANEDQKIGIEI IKRTLKI PAMTIAKNAGVEGSLI & 90 \\
\hline$----------------------------------------\mathrm{K}-\mathrm{S}---------------\mathrm{A}----------------------$ & 90 \\
\hline$-\mathrm{E}---\mathrm{H}---------\mathrm{V}-\mathrm{A}---\mathrm{V}--\mathrm{I}-\mathrm{VASK}-\mathrm{AD}-\mathrm{RGQ}----\mathrm{NV}--\mathrm{KVAL}-\mathrm{AMEA}-\mathrm{LRQ}-\mathrm{VL}-\mathrm{C}-\mathrm{E}-\mathrm{P}-\mathrm{VV}$ & 466 \\
\hline IE--VRNAK--------A---VT--QAA----K-KLTGE-EAT-AN-V-VA-EA-LKQ--F-S-M-PGVV & 465 \\
\hline VEKIMQSSSEVGYDAMAGDFVNMVEKGI IDPTKVVRTALLDAAGVASLLTTAEVVVTEI PKEEKDPGMGA & 560 \\
\hline$----\mathrm{L}-----\mathrm{I}-----\mathrm{L}------------------------------------\mathrm{A}----------------$ & 560 \\
\hline ANTVKGGDGNY--N-ATEEYG--IDM--L-----T-S--QY--S--G-MI-T-CM--DL--NDAADLGA- & 536 \\
\hline A--VRNL-VGH-LN-AT-EYEDLLKA-VA--V--T-S--QN--SI-G-FL-T-A--ADK-EKTAA-ASDP & 535 \\
\hline MGGMGGGMGGGMF & 30 \\
\hline------------- & 630 \\
\hline G-MG-M-GM---M & 506 \\
\hline T-----MDF & \\
\hline
\end{tabular}

Residues identical to the human HSP are indicated by dash. Significant sequence homology is found between mammalian and microbial HSP. E. coli-derived GloEL fragment and human HSP60 have $45.2 \%$ homology.

autoimmunity in patients with BD because of the molecular mimicry between human and microbial HSP. In this paper, we summarize current understanding of T-cell responses against HSP in patients with BD.

\section{HSP Expressions in BD Lesions}

Lehner et al. found that monoclonal antibodies against HSP65 reacted with six S. sanguinis strains and Streptococcus pyogenes [19]. They revealed that both IgG and IgA antibodies against HSP65 and S. sanguinis were significantly increased in $\mathrm{BD}$ patients compared to normal controls. They showed molecular mimicry between HSP and streptococcal antigens and suggested HSP-antigen-specific autoimmunity in the pathogenesis of $\mathrm{BD}$.

After the initial report, researchers tried to identify the expression of HSP and to analyze immune cell functions on biopsy specimens in patients with BD. Several researchers 
TABLE 2: Conserved peptide sequences of mycobacterial HSP65 and human HSP60 [20].

\begin{tabular}{|c|c|c|c|c|c|c|c|c|c|c|c|c|c|c|c|c|c|c|c|c|}
\hline Mycobacterial HSP65 & $(111-125)$ & $\mathrm{N}$ & $\mathrm{P}$ & $\mathrm{L}$ & G & $\mathrm{L}$ & $\mathrm{K}$ & $\mathrm{R}$ & G & I & E & $\mathrm{K}$ & A & $\mathrm{V}$ & E & $\mathrm{K}$ & & & & \\
\hline Human HSP60 & $(136-150)$ & $\mathrm{N}$ & $\mathrm{P}$ & V & $\mathrm{E}$ & I & $\mathrm{R}$ & $\mathrm{R}$ & G & $\mathrm{V}$ & M & $\mathrm{L}$ & A & $\mathrm{V}$ & $\mathrm{D}$ & A & & & & \\
\hline Mycobacterial HSP65 & $(154-172)$ & Q & S & I & G & $\mathrm{D}$ & $\mathrm{L}$ & I & A & $\mathrm{F}$ & A & M & $\mathrm{D}$ & $\mathrm{K}$ & $\mathrm{V}$ & G & $\mathrm{N}$ & $\mathrm{E}$ & G & $\mathrm{V}$ \\
\hline Human HSP60 & $(179-197)$ & K & $\mathrm{E}$ & I & G & $\mathrm{N}$ & I & I & $S$ & $\mathrm{D}$ & A & M & K & K & $\mathrm{V}$ & G & $\mathrm{R}$ & K & G & $\mathrm{V}$ \\
\hline Mycobacterial HSP65 & $(219-233)$ & $\mathrm{L}$ & $\mathrm{L}$ & $\mathrm{V}$ & S & S & K & V & $S$ & $\mathrm{~T}$ & V & K & $\mathrm{D}$ & $\mathrm{L}$ & $\mathrm{L}$ & $\mathrm{P}$ & & & & \\
\hline Human HSP60 & $(244-258)$ & $\mathrm{L}$ & $\mathrm{L}$ & S & $\mathrm{E}$ & $\mathrm{K}$ & K & I & S & S & I & Q & S & I & $\mathrm{V}$ & $\mathrm{P}$ & & & & \\
\hline
\end{tabular}

$\begin{array}{lllllllllllllllllllllllll}\text { Mycobacterial HSP65 } & (311-326) & \text { D } & \text { L } & \text { S } & \text { L } & \text { L } & \text { G } & \text { K } & \text { A } & \text { R } & \text { K } & \text { V } & \text { V } & \text { V } & \text { T } & \text { K } & \text { D }\end{array}$

$\begin{array}{llllllllllllllllllllllll}\text { Human HSP60 } & (336-351) & \text { Q } & \text { P } & \text { H } & \text { D } & \text { L } & \text { G } & \text { K } & \text { V } & \text { G } & \text { E } & \text { V } & \text { I } & \text { V } & \text { T } & \text { K } & \text { D }\end{array}$

The four peptide sequences were well conserved between human HSP60 and mycobacterial HSP65. Peptide 336-351 derived from human HSP60 effectively stimulated the pathogenic $\mathrm{T}$ cells in patients with BD [10, 20-22].

observed massive expressions of HSP60 in BD skin [23] and oral ulcer lesions $[24,25]$. HSP60 was expressed more diffusely [25] and intensely [23, 25] in BD lesions than those in other types of inflammation, such as oral lichen planus and recurrent aphthous stomatitis. Not only infiltrating cells but also vascular endothelial and epithelial cells expressed HSP60 in the BD skin lesions [25].

We reported excessive Th1 cell function and aberrant HSP expression in patients with BD [8-10]. HSP60 mRNA expression was found in PBMC and in intestinal tissues of BD but not in those of normal controls [8]. We found that infiltrating mononuclear cells, including CD4+ T cells, CD8+ T cells, and CD68+ macrophages, expressed HSP60, IFN $\gamma$, and IL-12 in the intestinal lesions in patients with $\mathrm{BD}[8,9]$. C-C type chemokine receptor (CCR) 5 and macrophage inflammatory protein (MIP) $1 \beta$, a Th1-related chemokine receptor and its ligand, were detected in the intestinal lesions in patients with $\mathrm{BD}$, and we suggested that CCR5/MIP1 $\beta$ interaction played a role in the migration of activated Th1 cells [8]. It is possible that HSP60 acted as a crucial signal to trigger excessive Th1 cell accumulation and subsequent Th1-cell-mediated inflammatory responses in the intestinal lesions in patients with BD where activated T cells and macrophages promoted the destructive processes.

\section{T-Cell Responses against HSP Peptides in Patients with BD}

Lehner et al. analyzed the frequency of short-term cell lines stimulated with four selected peptides (111-125, 154172, 219-233, 311-326) (Figure 1, Table 2) derived from Mycobacterium tuberculosis HSP65 in the ocular, arthritic, and mucocutaneous types of $\mathrm{BD}$. T cells from ocular-type $\mathrm{BD}$ patients responded excessively to the stimulation with the four HSP peptides, especially peptides 111-125 and 311-326 [20].

Excessive T- and B-cell responses to the four peptides and human counterparts were observed in patients with BD who lived in Europe, Far Eastern Asia, and the Middle East [10, 20-22].

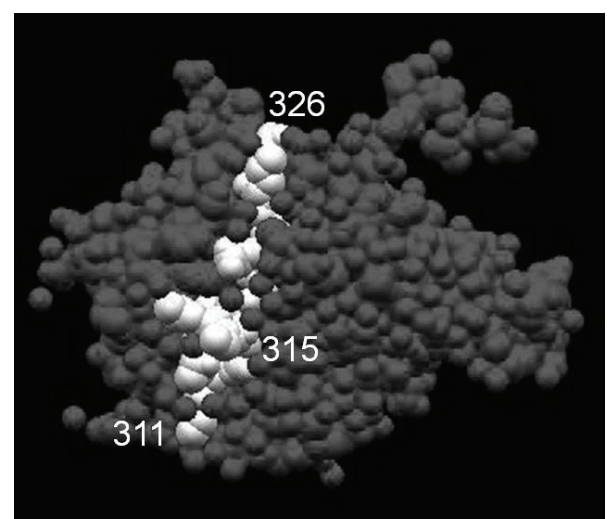

FIGURE 1: Crystal structure of HSP. GroEL fragment apical domain, a bacterial homologue of human HSP 60, comprising residues 191345 derived from Escherichia coli in the Protein Data Bank Japan (PDBj) is shown. Residues 311-326 which corresponded to human HSP60 331-356 are colored with white.

In our study, CD4+ T cells, but not CD8+ T cells, yielded proliferative responses to the peptide 336-351 derived from human HSP60 in Japanese BD patients [26]. We evaluated $\mathrm{T}$-cell receptor $\mathrm{V} \beta$ gene usage of $\mathrm{T}$ cells which responded to the peptide 336-351 in the patients [22]. To this end, we first conducted amplification by PCR of TCR V $\beta$ gene of $\mathrm{T}$ cells which had been stimulated with the peptide in vitro and then visualized several bands which represented each TCR clonotype by PCR-single-strand conformation polymorphism (SSCP) based technique. T-cell receptor $\mathrm{V} \beta$ gene oligoclonality was found in $\mathrm{T}$ cells which had been freshly isolated from peripheral blood and the exactly same PCR products were remarkably increased after stimulation with the peptide 336-351 in patients with BD. These data suggested that HSP-specific T cells in patients with BD showed antigen-driven expansion by HSP stimulation and that the HSP peptide reactive $\mathrm{T}$ cells increased in $\mathrm{BD}$ peripheral blood. A longitudinal study of the TCR clonotypes in $6 \mathrm{BD}$ patients showed that the oligoclonal expansion of particular T-cell clonotypes correlated with the severity of uveitis [22]. 


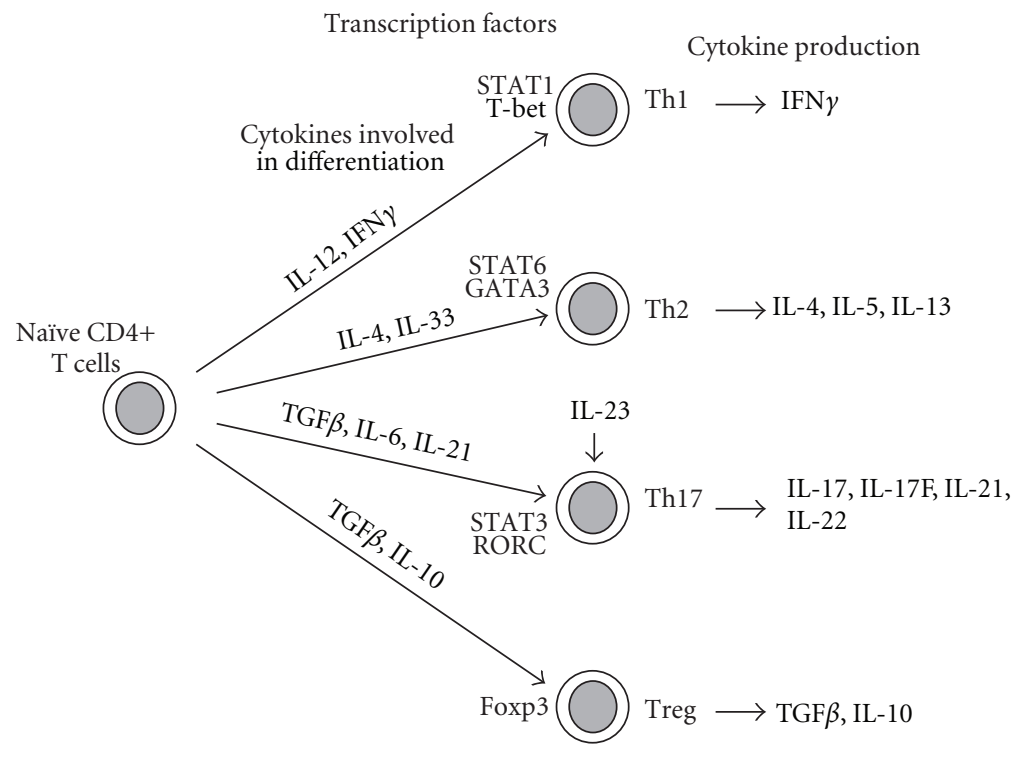

FIgure 2: Current view of CD4+ T-cell subsets in humans [27]. Naïve CD4+ T-cells differentiate into several T-cell subsets in the presence of appropriate cytokines. In response to the cytokines, the corresponding signaling molecules and transcription factors are expressed to regulate lineage commitments. Th17 cells require IL-23 for their expansion.

\section{4. $\gamma \delta$ T-Cell Activation and HSP60/65}

HSP60/65 presented by antigen presenting cells (APCs) stimulated not only $\alpha \beta \mathrm{T}$ cells but also $\gamma \delta \mathrm{T}$ cells which played important roles in the oral mucosal immunity as the first defense against microorganisms. It was thought that $\mathrm{V} \gamma 9 \delta 2+\mathrm{T}$ cells, a major subset of $\gamma \delta \mathrm{T}$ cells of peripheral blood lymphocytes $(\mathrm{PBL})$, recognized the antigens produced by bacteria [26]. $\mathrm{V} \delta 1+\gamma \delta \mathrm{T}$ cells responded to the stress inducible major histocompatibility complex class I related chain A (MICA) mainly expressed on damaged intestinal epithelial cells [28].

$\mathrm{V} \delta 2+\gamma \delta \mathrm{T}$ cells increased in peripheral blood, while $\mathrm{V} \delta 1+\gamma \delta \mathrm{T}$ cells increased in bronchoalveolar lavage fluid and cerebrospinal fluid in patients with BD [29]. Infiltrating cells expressed HSP, and $\gamma \delta$ T-cell numbers were increased in oral ulcer in the patients $[23,25]$.

We found that CD45RA $+\mathrm{V} \gamma 9 \delta 2+\gamma \delta \mathrm{T}$ cells increased in BD PBL irrespective of disease activity. $\mathrm{V} \gamma 9 \delta 2+\gamma \delta \mathrm{T}$ cells in the active phase of BD expressed IL- 2 receptor $\beta$ chain and HLA-DR, suggesting that the cells were activated in vivo [30]. The CD45RA $+\gamma \delta \mathrm{T}$ cells produced tumor necrosis factor (TNF) $\alpha$ and contained perforin granules. Moreover, $\mathrm{V} \gamma 9 \delta 1+$ $\gamma \delta \mathrm{T}$ cells preferentially responded to S. sanguinis-derived KTH1 antigen without HLA restriction [31]. It is possible that $\gamma \delta \mathrm{T}$ cells respond to HSP both in peripheral blood and in affected lesions and enhance the inflammation in patients with BD.

\section{Th17 Cells and HSP}

Recently, the classical Th1/Th2 paradigm was challenged by the discovery of various subsets of $\mathrm{T}$ helper cells [27] (Figure 2). Th17 cells produce a number of proinflammatory cytokines, including IL-17, IL-17F, IL-21, and IL-22. IL-6,
IL-21, and transforming growth factor (TGF) $\beta$ were reported to play a role in the differentiation of Th17 cells which proliferated in the presence of IL-23. Regulatory T (Treg) cells control T-cell immune responses and also need TGF $\beta$ for their differentiation [27] (Figure 2).

TGF $\beta$ activates Smad pathway via TGF $\beta$ receptor I/II complex and activated Smad protein leads to forkhead box P3 (Foxp3) expression which is a master gene of Treg cells [32] (Figure 3). TGF $\beta$ also activates p38 mitogenactivated protein kinase (MAPK) which regulates Th17 cell differentiation $[32,33]$. In the presence of TGF $\beta$, IL-6/STAT3 signaling pathway plays a critical role in the reduction of Foxp3 expression and in the induction of retinoic acid receptor-related orphan receptor $\mathrm{C}$ (RORC) expression which is a master gene of Th17 cells [34] (Figure 3). Also it is reported that STAT3 and MAPK are involved in the immune tolerance induction and Treg cell differentiation $[35,36]$. Signaling molecules such as STAT3 and MAPK may transduce positive and negative signals depending upon the surrounding microenvironment. To address these issues, further studies are needed. In addition, specific antigen such as HSP directly and indirectly regulated the balance between Th17 and Treg cells [37-40].

In patients with $\mathrm{BD}$, monocytes and $\mathrm{T}$ cells overproduced IL-6 in the presence of HSP [41]. Overexpression of RORC mRNA [42, 43], underexpression of Foxp3 [44, 45], and high frequencies of Th17 cells $[42-44,46]$ were reported in patients with BD. We recently reported that TGF $\beta / \mathrm{Smad}$ signaling pathway of $\mathrm{T}$ cells was overactivated in patients with BD [47]. We also reported the possibility that CD4+ $\mathrm{T}$ cells in patients with $\mathrm{BD}$ showed higher sensitivity to IL-23 and produced more IFN $\gamma$ and IL-17, as compared with normal controls [43]. Recent genome-wide association studies identified IL-12 receptor $\beta 2$ (IL-12R $\beta 2$ )/IL-23 receptor and IL-10 genes as BD susceptibility genes $[48,49]$. 


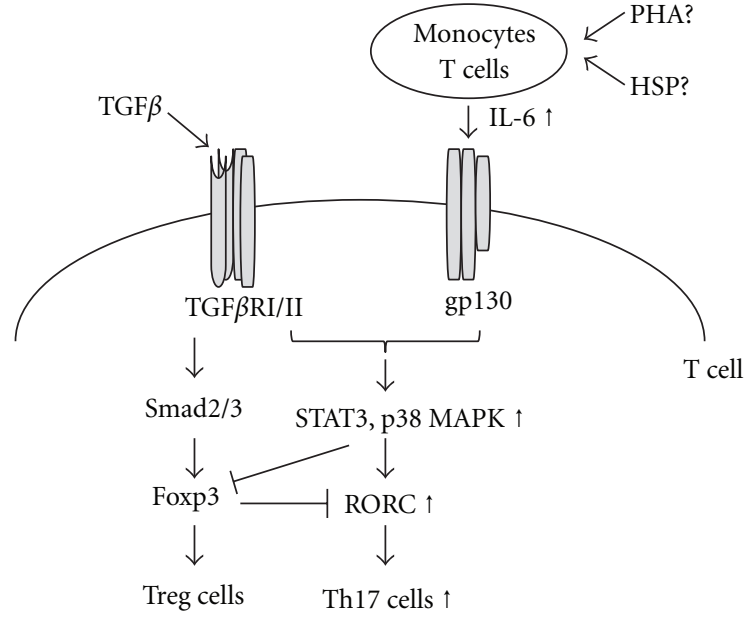

FIGURE 3: A schematic representation of skewed Th17/Treg cell differentiation in patients with $\mathrm{BD}$, a hypothesis. TGF $\beta$ activates Smad pathway via TGF $\beta$ receptor I/II complex, and activated Smad protein leads to forkhead box P3 (Foxp3) expression which is a master gene of Treg cells [27]. TGF $\beta$ also activates p38 mitogen-activated protein kinase (MAPK) which regulates Th17 cell differentiation $[32,33]$. In the presence of TGF $\beta$, IL-6/STAT3 signaling pathway plays a critical role in the reduction of Foxp3 expression and in the induction of retinoic acid receptor-related orphan receptor $\mathrm{C}$ (RORC) expression which is a master gene of Th17 cells [34]. In patients with BD, monocytes and $\mathrm{T}$ cells overproduce IL-6 in the presence of HSP [41]. Overexpression of RORC [42, 43], underexpression of Foxp3 [44, 45], and higher frequencies of Th17 cells $[42-44,46]$ are reported in patients with BD. PHA: phytohemagglutinin, TGF $\beta$ RI/II: TGF $\beta$ receptor types I and II, STAT3: signal transducer and activator of transcription 3.

Based on the above findings, we proposed that HSP induced imbalance of Th17 cells to Treg cells in patients with BD (Figure 3). Further study on HSP and Th17 cell differentiation is necessary to understand the pathogenesis of $\mathrm{BD}$.

\section{Toll-Like Receptors (TLRs) and HSP60/65}

TLRs play a key role in recognition of microbes in the innate immune system. Activation of dendritic cells by TLR ligands is a crucial event in the initiation of both innate and adaptive immune responses. Several classes of TLR ligands are identified which interact with distinct members of the TLR family. TLR2/CD14 complex and TLR4/CD14 complex were suggested to be important for APC to recognize HSP60 [50], and TLR2/ 6 heterodimer was reported to promote IL-6 production of mononuclear cells [51]. We need to study the expression of the heterodimer because IL- 6 concentrations were elevated in patients with BD [41].

We found that TLR2 and TLR4 mRNA were expressed on ileocaecal ulcer lesions of $\mathrm{BD}$, but less on unaffected sites of $\mathrm{BD}$ and on Crohn's disease lesions. We found that IL12 producing TLR2+ macrophages are located neighboring to CD3+ T cells. HSP60 was expressed on the same region of the intestinal lesions [9]. We suggested that TLR/HSP60 interactions induced destructive Th1-type responses at the intestinal lesion in patients with BD.

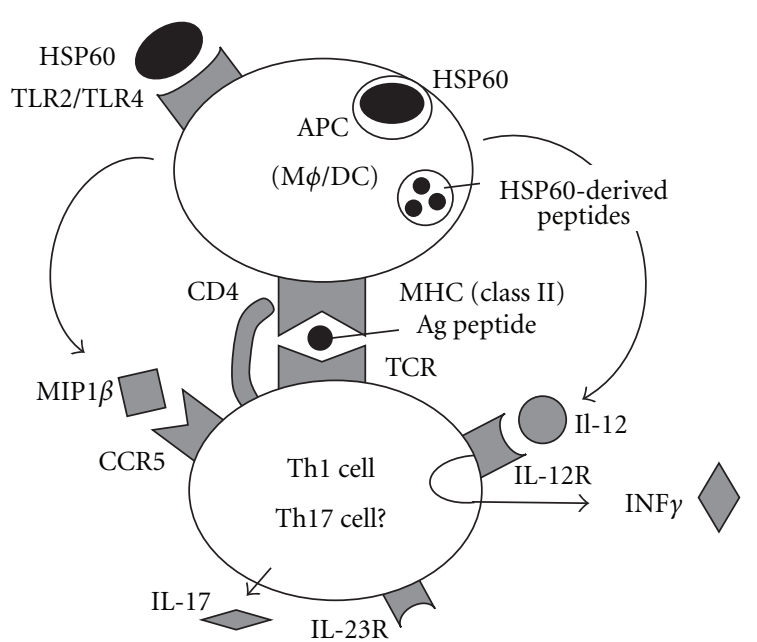

FIGURE 4: HSP60 regulates Th1 cell differentiation through multiple pathways, a hypothesis. The interactions between TCR- and HSPderived peptides on MHC [22] and between IL-12 and its receptor [8-10] may induce aberrant T-cell differentiation in patients with BD (Figure 4). The interaction between MIP1 $\beta$ and C-C-type chemokine receptor (CCR) 5 was suggested to induce migration of the pathogenic T cells [8]. TLR2/6 heterodimer is involved in IL-6 production [51] and thus we need to study the expression of the heterodimer in patients with $\mathrm{BD}$.

\section{Conclusions}

We reviewed here HSPs reactive T-cells and their contribution to the pathogenesis of BD. It is possible that HSPs regulate $\mathrm{T}$-cell differentiation through several interactions. The interactions between TCR- and HSP-derived peptides on MHC [22] and between IL-12 and its receptor [8-10] may induce aberrant T-cell differentiation in patients with BD (Figure 4). The interaction between MIP1 $\beta$ and CCR5 was suggested to induce migration of the pathogenic T cells [8]. TLR2/6 heterodimer is involved in IL-6 production [51] and thus we need to study the expression of the heterodimer in patients with BD. It is important to clarify whether HSP bring about generation of pathogenic Th17 cells in patients with BD because Th1 and Th17 cells share a common structure (IL-12R $\beta 1$ ) on their characteristic receptor complexes, namely, IL-12R and IL-23R [52].

\section{Acknowledgments}

This work was supported in part by grants from Behcet's Disease Research Committee, Research on Specific Disease of the Health Science Research Grants from the Ministry of Health, Labor and Welfare, Japan.

\section{References}

[1] T. Sakane, M. Takeno, N. Suzuki, and G. Inaba, "Behcet's disease," The New England Journal of Medicine, vol. 341, no. 17, pp. 1284-1291, 1999.

[2] M. Melikoglu, S. Uysal, J. G. Krueger et al., "Characterization of the divergent wound-healing responses occurring in the pathergy reaction and normal healthy volunteers," Journal of Immunology, vol. 177, no. 9, pp. 6415-6421, 2006. 
[3] M. Ben Ahmed, H. Houman, M. Miled, K. Dellagi, and H. Louzir, "Involvement of chemokines and Th1 cytokines in the pathogenesis of mucocutaneous lesions of Behçet's disease," Arthritis and Rheumatism, vol. 50, no. 7, pp. 2291-2295, 2004.

[4] S. Koarada, Y. Haruta, Y. Tada et al., "Increased entry of CD4+ T cells into the Th1 cytokine effector pathway during T-cell division following stimulation in Behçet's disease," Rheumatology, vol. 43, no. 7, pp. 843-851, 2004.

[5] H. Houman, A. Hamzaoui, I. Ben Ghorbal, M. Khanfir, M. Feki, and K. Hamzaoui, "Abnormal expression of chemokine receptors in Behçet's disease: relationship to intracellular Th1/Th2 cytokines and to clinical manifestations," Journal of Autoimmunity, vol. 23, no. 3, pp. 267-273, 2004.

[6] F. Ilhan, T. Demir, P. Türkçüoğlu, B. Turgut, N. Demir, and A. Gödekmerdan, "Th1 polarization of the immune response in uveitis in Behçet's disease," Canadian Journal of Ophthalmology, vol. 43, no. 1, pp. 105-108, 2008.

[7] A. M. Dalghous, J. Freysdottir, and F. Fortune, "Expression of cytokines, chemokines, and chemokine receptors in oral ulcers of patients with Behcet's disease (BD) and recurrent aphthous stomatitis is Th1-associated, although Th2-association is also observed in patients with BD," Scandinavian Journal of Rheumatology, vol. 35, no. 6, pp. 472-475, 2006.

[8] Y. Imamura, M. S. Kurokawa, H. Yoshikawa et al., "Involvement of Th1 cells and heat shock protein 60 in the pathogenesis of intestinal Behçet's disease," Clinical and Experimental Immunology, vol. 139, no. 2, pp. 371-378, 2005.

[9] K. Nara, M. S. Kurokawa, S. Chiba et al., "Involvement of innate immunity in the pathogenesis of intestinal Behçet's disease," Clinical and Experimental Immunology, vol. 152, no. 2, pp. 245-251, 2008.

[10] H. Nagafuchi, M. Takeno, H. Yoshikawa et al., "Excessive expression of Txk, a member of the Tec family of tyrosine kinases, contributes to excessive Th1 cytokine production by T lymphocytes in patients with Behcet's disease," Clinical and Experimental Immunology, vol. 139, no. 2, pp. 363-370, 2005.

[11] J. Y. Choe, W. T. Chung, S. W. Lee et al., "Regional distinction for the clinical severity of Behçet's disease in Korea: four university-based medical centre studies," Clinical and Experimental Rheumatology, vol. 28, no. 4, supplement 60, pp. S20-S26, 2010.

[12] G. Mumcu, T. Ergun, N. Inanc et al., "Oral health is impaired in Behçet's disease and is associated with disease severity," Rheumatology, vol. 43, no. 8, pp. 1028-1033, 2004.

[13] K. Yokota, S. Hayashi, Y. Araki et al., "Characterization of Streptococcus sanguis isolated from patients with Behcet's disease," Microbiology and Immunology, vol. 39, no. 9, pp. 729732, 1995.

[14] H. Yanagihori, N. Oyama, K. Nakamura, N. Mizuki, K. Oguma, and F. Kaneko, "Role of IL-12B promoter polymorphism in Adamantiades-Behcet's disease susceptibility: an involvement of Th1 immunoreactivity against Streptococcus sanguinis antigen," Journal of Investigative Dermatology, vol. 126, no. 7, pp. 1534-1540, 2006.

[15] Y. Mizushima, K. Hoshi, T. Matsuda et al., "Skin hypersensitivity to streptococcal antigens and the induction of systemic symptoms by the antigens in Behcet's disease-a multicenter study," Journal of Rheumatology, vol. 16, no. 4, pp. 506-511, 1989.

[16] International Study Group for Behçet's Disease, "Criteria for diagnosis of Behçet's disease," The Lancet, vol. 335, no. 8697, pp. 1078-1080, 1990.

[17] I. Fresko, H. Yazici, M. Bayramicli, S. Yurdakul, and C. Mat, "Effect of surgical cleaning of the skin on the pathergy phenomenon in Behcet's syndrome," Annals of the Rheumatic Diseases, vol. 52, no. 8, pp. 619-620, 1993.

[18] A. K. Dudani and R. S. Gupta, "Immunological characterization of a human homolog of the 65-kilodalton mycobacterial antigen," Infection and Immunity, vol. 57, no. 9, pp. 27862793, 1989.

[19] T. Lehner, E. Lavery, R. Smith, R. van der Zee, Y. Mizushima, and T. Shinnick, "Association between the 65-kilodalton heat shock protein, Streptococcus sanguis, and the corresponding antibodies in Behcet's syndrome," Infection and Immunity, vol. 59, no. 4, pp. 1434-1441, 1991.

[20] K. Pervin, A. Childerstone, T. Shinnick et al., "T cell epitope expression of mycobacterial and homologous human 65kilodalton heat shock protein peptides in short term cell lines from patients with Behcet's disease," Journal of Immunology, vol. 151, no. 4, pp. 2273-2282, 1993.

[21] H. Direskeneli, E. Ekşioğlu-Demiralp, S. Yavuz et al., "T cell responses to $60 / 65 \mathrm{kDa}$ heat shock protein derived peptides in Turkish patients with Behcet's disease," Journal of Rheumatology, vol. 27, no. 3, pp. 708-713, 2000.

[22] S. Kaneko, N. Suzuki, N. Yamashita et al., "Characterization of $\mathrm{T}$ cells specific for an epitope of human $60-\mathrm{kD}$ heat shock protein (hsp) in patients with Behcet's disease (BD) in Japan," Clinical and Experimental Immunology, vol. 108, no. 2, pp. 204-212, 1997.

[23] T. Ergun, Ü. Ince, E. Ekşioğlu-Demiralp et al., "HSP 60 expression in mucocutaneous lesions of Behçet's disease," Journal of the American Academy of Dermatology, vol. 45, no. 6, pp. 904-909, 2001.

[24] E. Deniz, U. Guc, N. Buyukbabani, and A. Gul, "HSP 60 expression in recurrent oral ulcerations of Behet's disease," Oral Surgery, Oral Medicine, Oral Pathology, Oral Radiology \& Endodontology, vol. 110, no. 2, pp. 196-200, 2010.

[25] T. E. Bramanti, N. P. Dekker, F. Lozada-Nur, J. J. Sauk, and J. A. Regezi, "Heat shock (stress) proteins and $\gamma \delta$ T lymphocytes in oral lichen planus," Oral Surgery, Oral Medicine, Oral Pathology, Oral Radiology \& Endodontology, vol. 80, no. 6, pp. 698-704, 1995.

[26] B. Altincicek, J. Moll, N. Campos et al., "Cutting edge: human $\gamma \delta \mathrm{T}$ cells are activated by intermediates of 2-C-methyl-Derythritol 4-phosphate pathway of isoprenoid biosynthesis," Journal of Immunology, vol. 166, no. 6, pp. 3655-3658, 2001.

[27] M. T. Palmer and C. T. Weaver, "Autoimmunity: increasing suspects in the CD4 + T cell lineup," Nature Immunology, vol. 11 , no. 1 , pp. 36-40, 2010.

[28] V. Groh, A. Steinle, S. Bauer, and T. Spies, "Recognition of stress-induced MHC molecules by intestinal epithelial $\gamma \delta \mathrm{T}$ cells," Science, vol. 279, no. 5357, pp. 1737-1740, 1998.

[29] K. Hamazaoui, A. Hamazaoui, F. Hentati " et al., "Phenotype and functional profile of T cells expressing $\gamma \delta$ receptor from patients with active Behçet's disease," Journal of Rheumatology, vol. 21, no. 12, pp. 2301-2306, 1994.

[30] N. Yamashita, H. Kaneoka, S. Kaneko et al., "Role of $\gamma \delta \mathrm{T}$ lymphocytes in the development of Behcet's disease," Clinical and Experimental Immunology, vol. 107, no. 2, pp. 241-247, 1997.

[31] M. Mochizuki, N. Suzuki, M. Takeno et al., "Fine antigen specificity of human $\gamma \delta \mathrm{T}$ cell lines $(\mathrm{V} \gamma 9+)$ established by repetitive stimulation with a serotype (KTH-1) of a grampositive bacterium, Streptococcus sanguis," European Journal of Immunology, vol. 24, no. 7, pp. 1536-1543, 1994.

[32] L. Lu, J. Wang, F. Zhang et al., "Role of SMAD and non-SMAD signals in the development of Th17 and regulatory T cells," Journal of Immunology, vol. 184, no. 8, pp. 4295-4306, 2010. 
[33] R. Noubade, D. N. Krementsov, R. Del Rio et al., "Activation of p38 MAPK in CD4 T cells controls IL-17 production and autoimmune encephalomyelitis," Blood, vol. 118, no. 12, pp. 3290-3300, 2011.

[34] E. Bettelli, Y. Carrier, W. Gao et al., "Reciprocal developmental pathways for the generation of pathogenic effector TH17 and regulatory T cells," Nature, vol. 441, no. 7090, pp. 235-238, 2006.

[35] R. Wang, G. Han, J. Wang et al., "The role of STAT3 in antigen-IgG inducing regulatory CD4+Foxp3+T cells," Cellular Immunology, vol. 246, no. 2, pp. 103-109, 2007.

[36] S. Huber, J. Schrader, G. Fritz et al., "P38 MAP kinase signaling is required for the conversion of CD4+CD25 - T cells into iTreg," PLoS ONE, vol. 3, no. 10, Article ID e3302, 2008.

[37] A. Zanin-Zhorov, L. Cahalon, G. Tal, R. Margalit, O. Lider, and I. R. Cohen, "Heat shock protein 60 enhances CD4+CD25+ regulatory $\mathrm{T}$ cell function via innate TLR2 signaling," The Journal of Clinical Investigation, vol. 116, no. 7, pp. 2022-2032, 2006.

[38] S. Pawaria and R. J. Binder, "CD91-dependent programming of T-helper cell responses following heat shock protein immunization," Nature Communications, vol. 2, article 521, 2011.

[39] G. H. M. van Puijvelde, T. van Es, E. J. A. van Wanrooij et al., "Induction of oral tolerance to HSP60 or an HSP60peptide activates t cell regulation and reduces atherosclerosis," Arteriosclerosis, Thrombosis, and Vascular Biology, vol. 27, no. 12, pp. 2677-2683, 2007.

[40] Y. T. Lin, C. T. Wang, M. E. Gershwin, and B. L. Chiang, "The pathogenesis of oligoarticular/polyarticular vs systemic juvenile idiopathic arthritis," Autoimmunity Reviews, vol. 10, no. 8, pp. 482-489, 2011.

[41] S. Pay, I. Şimşek, H. Erdem, and A. Dinç, "Immunopathogenesis of Behçet's disease with special emphasize on the possible role of antigen presenting cells," Rheumatology International, vol. 27, no. 5, pp. 417-424, 2007.

[42] K. Hamzaoui, E. Bouali, I. Ghorbel, M. Khanfir, H. Houman, and A. Hamzaoui, "Expression of Th-17 and ROR $\gamma \mathrm{t}$ mRNA in Behçet's Disease," Medical Science Monitor, vol. 17, no. 4, pp. CR227-CR234, 2011.

[43] J. Shimizu, K. Takai, N. Fujiwara et al., "Excessive CD4+ T cells co-expressing interleukin-17 and interferon-ã in patients with Behçet's disease," Clinical and Experimental Immunology, vol. 168, no. 1, pp. 68-74, 2012.

[44] G. Geri, B. Terrier, M. Rosenzwajg et al., "Critical role of IL-21 in modulating TH17 and regulatory T cells in Behçet disease," Journal of Allergy and Clinical Immunology, vol. 128, no. 3, pp. 655-664, 2011.

[45] Y. Nanke, S. Kotake, M. Goto, H. Ujihara, M. Matsubara, and N. Kamatani, "Decreased percentages of regulatory $\mathrm{T}$ cells in peripheral blood of patients with Behcet's disease before ocular attack: a possible predictive marker of ocular attack," Modern Rheumatology, vol. 18, no. 4, pp. 354-358, 2008.

[46] W. Chi, X. Zhu, P. Yang et al., "Upregulated IL-23 and IL-17 in Behçet patients with active uveitis," Investigative Ophthalmology and Visual Science, vol. 49, no. 7, pp. 30583064, 2008.

[47] J. Shimizu, T. Izumi, N. Arimitsu et al., "Skewed TGF $\beta /$ Smad signaling pathway of T cells in patients with Behcet's disease," Clinical and Experimental Rheumatology. In press.

[48] N. Mizuki, A. Meguro, M. Ota et al., "Genome-wide association studies identify IL23R-IL12RB2 and IL10 as Behçet's disease susceptibility loci," Nature Genetics, vol. 42, no. 8, pp. 703-706, 2010.
[49] E. F. Remmers, F. Cosan, Y. Kirino et al., "Genome-wide association study identifies variants in the MHC class I, IL10, and IL23R-IL12RB2 regions associated with Behçet's disease," Nature Genetics, vol. 42, no. 8, pp. 698-702, 2010.

[50] A. Kol, A. H. Lichtman, R. W. Finberg, P. Libby, and E. A. Kurt-Jones, "Cutting edge: heat shock protein (HSP) 60 activates the innate immune response: CD14 is an essential receptor for HSP60 activation of mononuclear cells," Journal of Immunology, vol. 164, no. 1, pp. 13-17, 2000.

[51] J. Jin, D. J. Samuvel, X. Zhang et al., "Coactivation of TLR4 and TLR2/6 coordinates an additive augmentation on IL-6 gene transcription via p38MAPK pathway in U937 mononuclear cells," Molecular Immunology, vol. 49, no. 3, pp. 423-432, 2011.

[52] D. A. Vignali and V. K. Kuchroo, "IL-12 family cytokines: immunological playmakers," Nature Immunology, vol. 13, no. 8, pp. 722-728, 2012. 


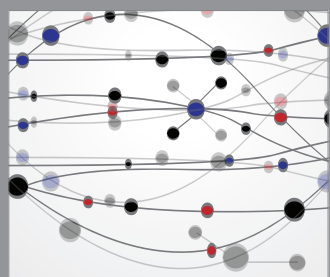

The Scientific World Journal
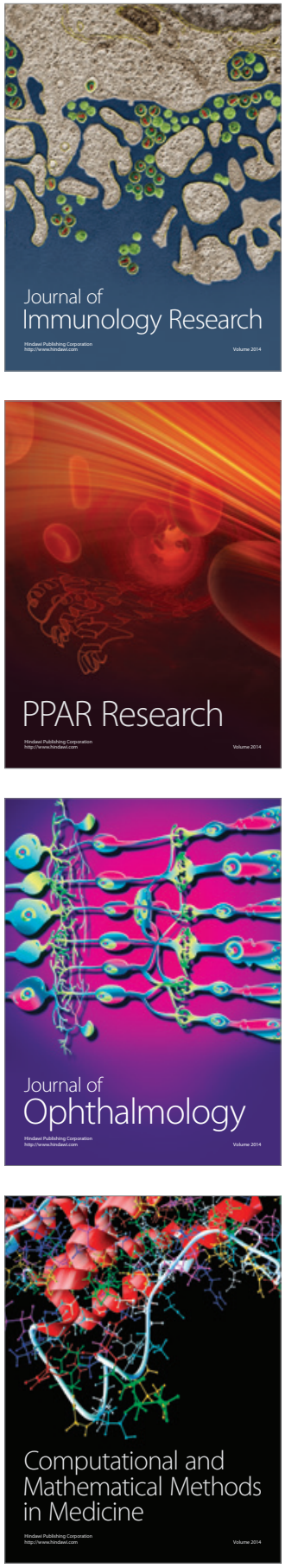

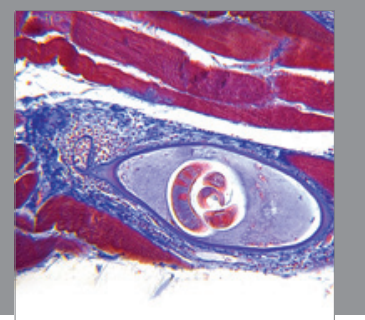

Gastroenterology

Research and Practice
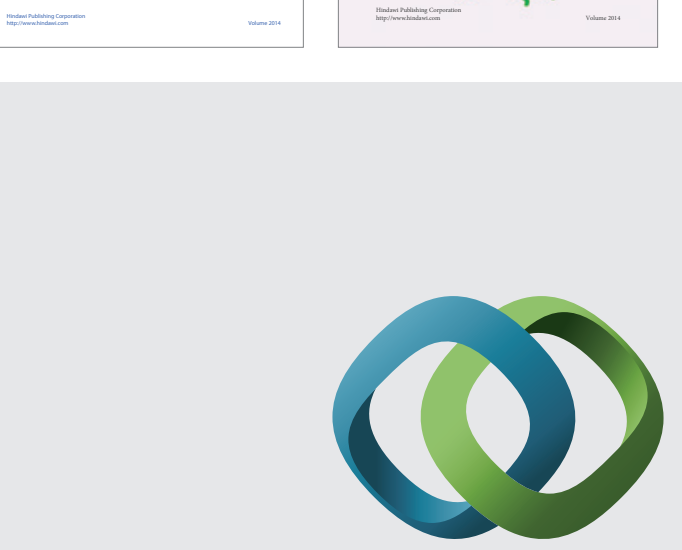

\section{Hindawi}

Submit your manuscripts at

http://www.hindawi.com
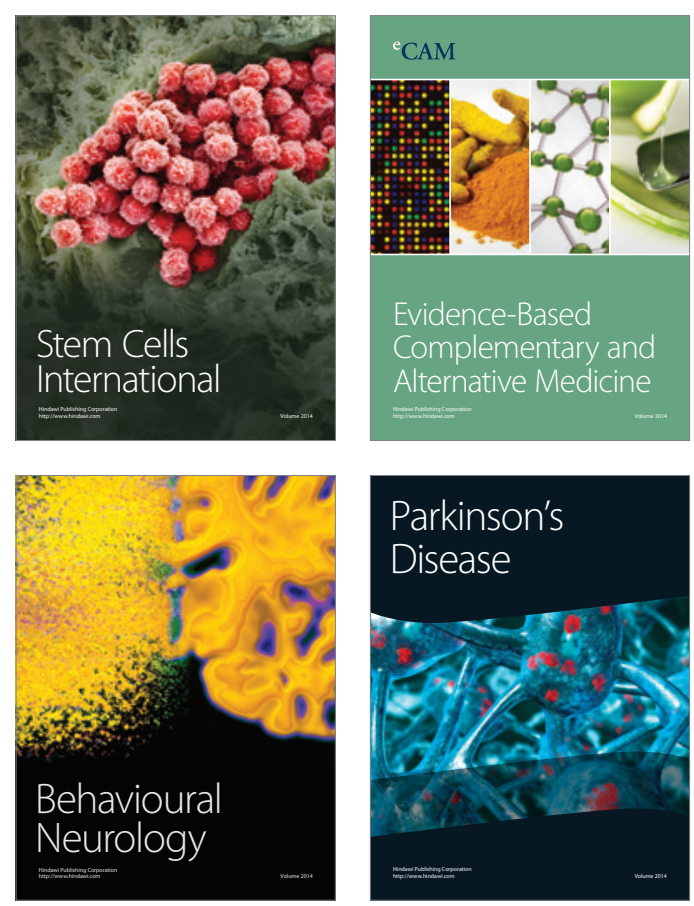

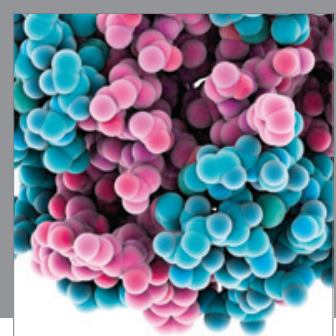

Journal of
Diabetes Research

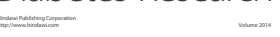

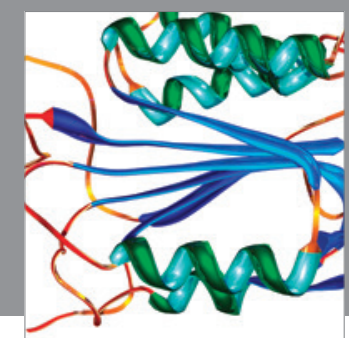

Disease Markers
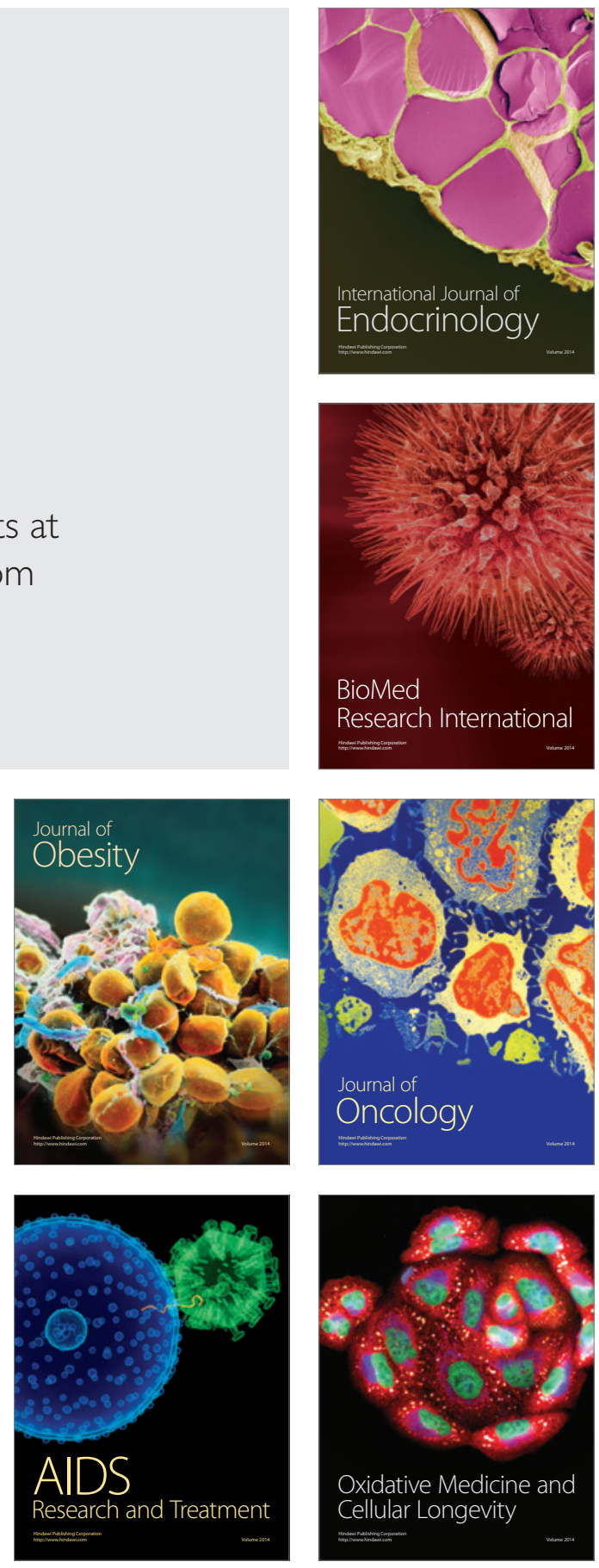